\title{
PRODUÇÃO E PURIFICAÇÃO DE UMA $\beta$-XILOSIDADE DO FUNGO CERATOCYSTIS FIMBRIATA
}

\author{
Marcele Pandeló Martins*, Gabriela Píccolo Maitan-Alfenas, Lorena \\ Gusmão Alvarenga Lage, Valéria Monteze Guimarães.
}

\begin{abstract}
Departamento de Bioquímica e Biologia Molecular, Universidade Federal de Viçosa, 36570-900. Viçosa, Brasil. *marcelepandelo@hotmail.com
\end{abstract}

\section{Resumo}

As $\beta$-xilosidases catalisam a hidrólise de xigooligossacarídeos através da remoção de unidades xilosil em sua região não redutora. Estas são enzimas de interesse biotecnológico, principalmente para produção do álcool combustível. Ceratocystis fimbriata é um fungo fitopatogênico causador doenças em diversas culturas. O objetivo deste trabalho foi cultivar o fungo $C$. fimbriata para produção da enzima $\beta$-xilosidase, purificar, determinar sua massa molecular e tentar comprovar sua identidade. $\mathrm{O}$ fungo foi cultivado por $168 \mathrm{~h}$ em meio mínimo mineral contendo farelo de trigo como fonte de carbono. Após este período, o meio foi filtrado, centrifugado e utilizado como fonte de $\beta$ xilosidases. A enzima foi purificada por cromatografia de troca iônica, ultrafiltração, e eletroforese em gel de poliacrilamida, obtendo 5 bandas no total. Para determinação da banda correspondente à enzima, fez-se um zimograma com o substrato sintético $\rho N P \beta x i l$. Logo após, a banda correspondente a $\beta$ xilosidase foi submetida a uma etapa de tripsinização em gel e posterior fragmentação em espectômetro de massa MALDI TOF/TOF com análise no MASCOT para busca referente a proteínas de fungos na base de dados do NCBI. Em todas as etapas foram realizadas atividades enzimáticas com $\rho N P \beta x i l$ para verificação da presença da enzima. Observou-se que as etapas de purificação foram eficientes por se obter a enzima purificada, sem grande perda de sua atividade, sendo a massa molecular desta, estimada em $161 \mathrm{kDa}$ pela eletroforese em gel. Na análise por espectometria, obteve-se baixa similaridade com a proteína hipotética PANT_20d0003 da levedura Pseudozyma antarctica T-34. Entretanto não há dados disponíveis nos bancos de dados referentes a enzimas de $C$. fimbriata, comprometendo esta análise. Os resultados indicam que a enzima é

Martins, Marcele Pandeló; "PRODUÇÃO E PURIFICAÇÃO DE UMA $\beta$-XILOSIDADE DO FUNGO CERATOCYSTIS FIMBRIATA", p. 13-14 . In: Anais da V Jornada Acadêmica Internacional de Bioquímica [= Blucher Biochemistry Proceedings, v.1, n.1]. São Paulo: Blucher, 2015. 
uma $\beta$-xilosidase e novos experimentos devem ser realizados para o estudo das aplicações biotecnológicas desta enzima.

Palavras-chave: $\beta$-xilosidase, Ceratocystis fimbriata, espectrometria de massas

Apoio financeiro: $\mathrm{CNPq}$, FAPEMIG 